\title{
SHORTER CONTRIBUTIONS AND DISCUSSIONS.
}

\section{LE DANTEC'S WORK ON BIOLOGICAL DETERMINISM AND CONSCIOUS PERSONALITY.'}

The recent work of $M$. Le Dantec on biological determinism and conscious personality seems to me likely to perform a great service, since it expresses with remarkable precision, if I may say so, the confusion of ideas and words that has been tending to insert itself for some years into philosophical language; as a consequence this book may with advantage serve as occasion for a discussion which has really a more general range.

Let us say at the outset, to put ourselves in touch with M. Le Dantec, that this prolific author has published, within the last two or three years, a number of biological papers on the mechanism of digestion and on theories of life; he has, moreover, conceived a new theory of life, which I have already noticed in this Review. His present volume is a continuation and development of the same ideas; the author endeavors to support two principal propositions: first, that the phenomena of consciousness have no sort of influence on material biological phenomena; and second, that the atoms and the molecules, not only of organic bodies, but also of inert substances, are endowed with consciousness. We shall not take up these two propositions directly, but shall discuss them as we trace the course of false ideas which the author has followed, in common with many of his contemporaries.

I wish to show, as briefly as possible, that five or six radically distinct notions have been completely confounded, and that this unfortunate confusion owes its origin to an inexact interpretation of the idea of freedom and of its contrary, determinism. Men have implicitly assumed-and that generally without being aware of the fact-that this notion of determinism is logically linked to certain other notions, and forms one with them. I shall endeavor to show the contrary, by defining anew the notions of determinism, mechanism, physiological functions, mental functions, spontaneity, and choice.

'Translated from the author's MS. by Professor H. C. Warren. 516 
1. Determinism. - Determinism, in the very broad meaning which it received from Claude Bernard, expresses the law of universal causation; it means that there is no phenomenon without a cause, that the succession of phenomena is regular and determinate; in still other terms, it is the negative of freedom, contingency, and incoherence. Most scientists to-day admit the determinism of phenomena of the physical order; as to psychological determinism - the position opposed to that of free-will-it is accepted by some and rejected by others; the two chief arguments that are urged in opposition to it are that it compromises moral responsibility and contradicts the inner sense which every one possesses of his own free-will. I am not debating any theory now, consequently I need not take either side. To sum up, there exist two forms of determinism, physical determinism and psychological determinism; against the first is urged the doctrine of the contingency of the laws of nature, and against the second the doctrine of free-will.

2. Mechanism. - This is a concept radically distinct from the preceding; it is one of those which have been expressed in the greatest number of different terms, and which have consequently suffered most from equivocality. Let us, first of all, define the concept itself. In man the acts of thought, voluntary movements, etc., are of a twofold nature; they are at once physiological phenomena, occurring in the nervous system, and phenomena of consciousness. Many philosophers have supported the idea that the phenomenon of consciousness is an epiphenomenon-something superadded, which does not intervene in the series of physiological modifications, but whose roble is that of a passive witness. Huxley was one of the most strenuous partisans of this theory, which he expressed in several striking figures; he compares consciousness to the shadow which follows the footsteps of the traveler without affecting his progress; or to light, which may illumine the wheels of a machine without exercising the slightest influence upon its functions. In France, Ribot for some time accepted this conception and popularized it; but he afterwards rejected it.

There are, indeed, some points of contact between determinism and mechanism; nevertheless these two concepts are quite distinct. One may be a determinist, for instance, without being a mechanist; one may admit that all phenomena are subject to the law of causation, and at the same time admit that the phenomena of consciousness play an active rôle, are influenced by physical phenomena, and influence them in turn; this is the theory of the mutual infuence of the physical and the moral, a theory which is just the opposite of mechanism. 
Some authors have been either unwilling or unable to make the distinction which we point out; confusing the two concepts together, they have maintained that consciousness is a useless attribute of living matter, because, if it were otherwise and consciousness could have any influence whatever on the succession of phenomena, this would be a denial of the law of causation. An example of this is met with in Le Dantec's book, when he maintains that " everything would come to pass just the same in the world if plastic substances possessed simply their physical and chemical properties, to the exclusion of the property of consciousness "- the mechanistic theory; he seems to have been led to this theory by the deterministic theory, which he expresses as follows: "Plastic substances, like all other inert substances, are subject to the law of inertia." We will not say that this author has confused these two concepts; but if he has distinguished them he has yet established between them a bond of solidarity which he supposes to hold of itself and which he does not justify in any other way.

One word more: the theory which we call mechanism has been most often designated by the name of automatism. I have not used this word, and indeed I am taking care to banish it from this article, since it is a word equivocal to the last degree. It has been given, as Morgan has recently shown, five or six entirely different meanings; men have called automatic an habitual act, a non-reflexive act, an act which is unaccompanied by consciousness, an act which is conscious but necessary and determined, etc. One can never be sure of himself in using it.

3. Physiological function: another notion which has become singularly obscure. Let us recall first some simple facts. We do not yet know the inner nature of the material phenomena which occur in a nerve center, in its cells and its nerves, when that center becomes active; it has nevertheless been held that many of the material modifications which occur there are chemical reactions; thus for a long time it has been maintained that vision has for its starting point a photo-chemical action in the retina, and quite recently Frey has gone so far as to suppose that the simple stimulation of the tactile papillæ is propagated by means of a chemical reaction which the contact sets up in the papilla or in the neighboring cells. However this may be, there still remains an essential difference between a chemical reaction set up in a test-tube and a physiological process properly so called; the latter is composed of a series, a chain of reactions, which mutually command and influence one another-which, in a word, are organized. Now this notion, so simple and natural, of the physiological 
process, has been greatly obscured of late; some authors have rejected it, thinking that it involved a denial of physical determinism.

It is in connection with the life and relations of micro-organisms that this confusion has come about. Here is a little infusorian swimming in a drop of water under the microscope; it goes, comes, turns about, stops beside the nutritive particles suspended in the liquid, then starts off again, changes its direction, stops, etc. Men sought to explain the movements of this little creature; it was observed that these movements are, to a certain extent, under the voluntary control of the experimenter who watches them through the microscope; he is able, by means of appropriate stimuli, such as light, the electric current and certain chemical substances, to excite the same movements, known in advance and possible to foresee as a whole, in these micro-organisms. What do these ingenious experiments of Verworn, Pfeffer and others prove? Certainly that the movements of these creatures are determined. But it does not follow from this that they are simply chemical reactions. Men have wrongly believed that in order to express their determinateness it was necessary to assimilate them to chemical reactions; and then, under the pen of certain scientists, the strangest analogies have been evolved: Le Dantec (Théorie nouvelle de la Vie, p. 32) goes so far as to compare the infusorian in movement to a piece of potassium turning about in the water which it decomposes, and pushed mechanically by a stream of hydrogen and oxygen. This extraordinary comparison is only justified by the desire to prove that nothing is left to chance in the movement of these little creatures, and that all their movements are explicable by physical causes-the deterministic position. But the deterministic position in no wise implies the conclusion that the movements in question are not physiological reactions.

Another very curious example. We know that the living bacteria contained in a preparation mass themselves at the points where a release of oxygen is taking place; the same is true of the leucocytes in the blood. Some years ago, wishing to express the constancy and necessity of the movement of bacteria towards oxygen, an eminent physiologist explained these characteristics by a chemical attraction operating between the body of the bacteria and the molecules of oxygen. This was evidently nothing but a lapse into polemics!

4. Spontaneity.-The notion of spontaneity is very important both in psychology and in physiology. It is contrasted with that of a stimulated or a reflex act. A reflex act is one which follows directly upon external stimulation; it is the response, or echo to it; it would 
not have been produced if this external stimulation had not taken place. A spontaneous act is one which does not directly respond to external irritation; it is produced by a memory, an act of reasoning, or an internal physiological cause, as for example the circulation of the blood. From every standpoint, not only from that of science, but also from that of practice and even of law, there is the greatest interest in distinguishing between spontaneous acts and stimulated acts; the former are in general more reflective; they are more personal to their author; they carry a greater juridical and moral responsibility. This is, therefore, a useful distinction and one which should be preserved. Many authors have sought to abolish it and to condemn the use of the term spontaneity as being unscientific. Why? It is easy to guess. These authors have misunderstood the meaning of the word spontaneous; they imagine that spontaneity means first cause, the absence of determination, and that it is a synonym for freedom.

5. Choice.-This word is probably the one that has occasioned the greatest amount of equivocation. It seemed as if the faculty of choosing implied free-will, and that if this faculty were accorded to any animalcule he was thereby removed from the influences of environment, and all determinism was suppressed. The responsibility for this confusion of ideas certainly rests upon the philosophers; it is they who, in the discussion of the free-will position, have represented choice as a demonstration of that position. A falling stone does not choose, it has been said, because its fall is determined by the laws of gravitation, whereas a thinking being can choose between several different courses; this is proof of his possessing a free/will. We need not enter into this discussion. Our aim is to show that apart from every theory, laying aside that of free-will and even admitting a determinism that is universal and without exception, it is possible to give a specific meaning to the word choice. We may again take an example from among the micro-organisms. It has been asked whether certain species of infusoria do not exercise choice in the matter of their nutrition. There are infusorian hunters, who traverse the waters of pools with their mouths open and their cilia always in motion, and who swallow all the particles suspended in the water, drawing them towards their mouth by the current which they produce with their peristome. These creatures, then, do not exercise choice at all; provided the particle be of a suitable size it is mechanically introduced into the mouth; it reaches the plasm of the body, and there it is either assimilated or rejected, according to its nature. The problem is to discover whether other infusoria do not choose their food before swallow- 
ing, that is, whether the stimulation produced by the food does not, by a reflex route, excite a movement of prehension or rejection according to the nature of the food. Observation alone can give an answer to this problem. Whichever way it be resolved, it has at least been possible to propose it, and it has been proposed without any question of free-will; for choice, thus understood, is composed of a series of regular and rigorously determined reflexes.

6. Psychic functions. It is here that the greatest errors have accumulated-as it were, by choice! To a number of our contemporaries, little versed in psychology-which fact does not prevent them from constructing wretched psychology without knowing it-the phenomena of consciousness present a sort of phantasy, or phantasmagoria without cause and without law. We need not reply that a phenomenon of consciousness appears to us to be as rigorously determined, in its production, its quality and its minutest details, as the fall of a stone or the budding of a plant; but it is useless to stop over this point, since these are errors which it is only necessary to clearly set forth in order to refute with the same stroke. Let us follow out the effects of this preconceived idea on the interpretation of phenomena. The question comes up again in the interpretation of the movements and acts performed by micro-organisms. Some authors wishing to endow micro-organisms with psychic properties-a disputable point, be it understood, on which only hypothesis can be made-the principal objection raised against this interpretation consists in a naïve declaration that this would mean the suppression of fixed laws. "Here is a bacterium," says Le Dantec, "which starts off for a region of the infusion where he will find a substance which pleases him(!) I direct a ray of blue light upon him from another side, and he is compelled to change his route. But, it will be said, this is because he likes the light better than the food. Then I coax him in another direction by means of an attractive substance which is, however, noxious to him; he rushes up to it and dies from its effects; is this because I annoy him to such an extent that he commits suicide?"

This ironical method of reasoning is not peculiar to the author whom we cite; it may be considered as a very fair sample of the arguments of a certain number of physiologists. As regards M. Le Dantec himself, it is only necessary to notice this rather unexpected fact, that although he refuses to the infusorian, in the preceding passage, the faculty of being pleased with a substance, he, nevertheless, does not hesitate to accord consciousness to atoms of iron and chlorine. ${ }^{1}$

1 Vide some savory lines on the azotic consciousness and the atomic consciousness, as opposed to the molecular consciousness, p. 84 . 
But there is no need of stopping over the question whether infusoria possess any rudiments of consciousness and sensibility; in the present article I do not propose to interpret observations or to fight for a theory. I limit myself to a criticism of ideas, and from this standpoint I find that the principal objection advanced against those who wish to allow psychical faculties to the protozoa is that such psychical faculties would be the expression of arbitrariness and phantasy, that they would be incompatible with the idea that "every operation performed by a protozoan depends solely on the conditions of environment and being under determinate conditions is itself determinate."

In a word, to place well in relief the matrix-idea of all the contradictions which have been noted, we may say that there exists, even among the best minds, a tendency to admit that determinism applies less vigorously to living matter than to inert matter, to the facts of consciousness than to the facts of physics, to complex phenomena than to simple phenomena.

Alfred Binet.

SORBONAR, PARIS.

\section{A NEW FACTOR IN WEBER'S LAW.}

Does Weber's law depend upon the real or upon the apparent stimulus? It has always been assumed that it depends upon the socalled real physical stimulus. The measurements of some illusions ${ }^{2}$ led me to question this and investigate whether it depends upon the apparent stimulus, and if so, according to what law.

To illustrate the theory I will state its application to the results of a series of experiments made for the purpose of testing this matter in the illusion of weight, which is due to the difference in size of bodies that have the same weight. (For details in regard to the measurements of this illusion, see article cited, pp. 1-29.) The apparatus consisted of three pairs of cylinders- $A, B$ and $C$-each of the same weight, $80 \mathrm{~g}$.; the same diameter, $37 \mathrm{~mm}$. ; and varying in height, $A$ being $20 \mathrm{~mm}$., $B, 120 \mathrm{~mm}$., and $C, 50 \mathrm{~mm}$. With these I measured (I) the threshold, or least perceptible difference, and (2) the amount of illusion in $A$ and $B$ respectively when measured by $C$ as standard.

Representing the threshold value by $\Delta$, the results are (I) $\Delta A=2.8 \mathrm{~g} ., \Delta B=4.0 \mathrm{~g} ., \Delta C=3.3 \mathrm{~g} . ;$ and $(2)$ the illusion in $A$ as measured by $C(K)$, is an overestimation of $15.8 \mathrm{~g}$, and the illusion in

Stud. Yale Psyck. Lab., I895, III., I-67. 